Article

\title{
Social Media as a Disguise and an Aid: Disabled Women in the Cyber Workforce in China
}

\author{
Jing Zheng ${ }^{1}$, Yuxin Pei ${ }^{2, *}$ and Ya Gao ${ }^{2}$ \\ ${ }^{1}$ Department of Sociology, Shenzhen University, 518060 Shenzhen, China; E-Mail: zj@szu.edu.cn \\ 2 Department of Sociology \& Social Work, Sun Yat-sen University, 510275 Guangzhou, China; \\ E-Mails: peiyuxin@mail.sysu.edu.cn (Y.P.), gaoya_926@163.com (Y.G.) \\ * Corresponding author
}

Submitted: 26 November 2019 | Accepted: 26 March 2020 | Published: 28 April 2020

\begin{abstract}
Existing literature shows that people living with physical impairment are systematically disadvantaged in the workforce and their voices are often silenced. With a perspective of intersectionality, this article looks into how disabled women suffer from multiple forms of discrimination and how social media may emerge as a tool of empowerment for them in both the workforce and their everyday lives. Drawing on five cases of Chinese disabled women in the cyber workforce, the study finds that the booming Internet economy enables more disabled women to financially support themselves. Social media appears as a cover for these women to disguise their disability identity and get more job opportunities. It serves as an aid in many cases to allow these women to increase social participation, to project their voice, and to form alliances. The risks and challenges that disabled women often encounter in the cyber workforce are also discussed.
\end{abstract}

\section{Keywords}

disabled women; employment; physical impairment; social media; work discrimination; work inclusion

\section{Issue}

This article is part of the issue "Left Behind? Women's Status in Contemporary China" edited by Robert Walker (Beijing Normal University, China) and Jane Millar (University of Bath, UK).

(C) 2020 by the authors; licensee Cogitatio (Lisbon, Portugal). This article is licensed under a Creative Commons Attribution 4.0 International License (CC BY).

\section{Introduction}

How Does It Feel To Be a Disabled Person Sitting in a Wheelchair? This is the title of the first video clip Nana, a patient with brittle bone disease, put online as a vlogger. In this video, she used a voice changer to alter her pitch and voice speed, telling people her experience as a wheelchair user. She changed many outfits to cosplay different people, sharing her observations and thoughts in a hilarious way. The video attracted more than ten thousand viewers. After that, she was invited to sign up with a live streaming company and create her own channel on this platform. Nana is very excited about this opportunity. This employment not only brings her a stable income, it also fulfills her wish to help other people understand more about the lives of disabled people.
People who are with physical impairments are systematically disadvantaged in the workforce and their voices are often silenced. For working disabled women, the predicament is even worse. Existing literature has documented the multiple forms of discrimination they encounter compared to working men with and without disabilities (Randolph, 2005). As a result of being negatively stereotyped as weak and incapable, they often find it difficult to demonstrate their competencies. In some cases, to avoid reminding their colleagues of their disability and exposing themselves to negative attitudes, they even refrain from disclosing their disability or requesting accommodations at work (Moloney, Brown, Ciciurkaite, \& Foley, 2019).

In China, although disabled people encounter new difficulties and challenges resulted from social changes 
such as the privatization of health care system and dismantling of the rural cooperative medical system, they benefit from the developing market economy and their participation in the labor market has been encouraged by the government through tax incentives and employment services (Kohrman, 2005; Shang, 2000). In addition, a range of personal narratives of disability experience has been published since the 1980s, increasing the visibility of disabled people in the current Chinese cultural and social context (Dauncey, 2012, 2013). However, examined with a gender lens, the situation remains worrisome. For example, despite its praiseworthy achievements, the China Disabled Persons' Federation (the most important and well-known quasi-governmental disabled persons' organization in China) is also criticized for some of its practices that reinforce gender inequality. The fact that this entity is run predominately by men and that its intervention program of providing three-wheeled motor bikes to increase economic and social inclusion of disabled people was limited to urban men with walking difficulties are cases in point (Kohrman, 2005). Such practices perpetuate the stigmatic notion that men are more competent and more likely to achieve institutional success. Also, within the bourgeoning trend of self-representation and self-advocacy of disabled people both on an individual and group level (Dauncey, 2013), disabled men seem to have more opportunities to have their voice heard and their experience understood (Dauncey, 2017). Less is known about disabled women's endeavor to live economically positive lives in contemporary Chinese society.

In this article, through the cases of five disabled women strategically using the Internet to seize job opportunities to financially support themselves and to increase social participation, we discuss how Internet access may provide new routes to economic and social inclusion for people with disabilities. While demonstrating how cyberspace facilitates the empowerment of working disabled women, we also call attention to the risks and challenges faced by these women in the cyber workforce such as cyberbullying, harassment, insufficient skills, and lack of competitive edge.

\section{Literature Review}

Most of the literature on disabled women examines how disability and gender intersect to compound negative outcomes for these women. Some studies center on the theorization of intersectionality and elaborate how disability relates to a critical category in the important concerns of feminist theory, calling for the reimagining of disability and the liberation of both disabled and nondisabled people from oppressive narratives. For example, based on close readings of literary texts of the eighteenth century, Deutsch and Nussbaum (2000) argue that notions such as defect and deformity could be precursors of modern concept of race. The discriminative ideology that designates femaleness as a defect could be in the same vein of cultural meanings as these derogative no- tions, which makes the intersectional analysis of gender, race, and disability meaningful. Built on a systematic review of research in the field, Garland-Thomson (2005) points out that the available cultural narratives of disability are often disempowering and oppressive. Meanwhile, in the similar way that disability studies challenge the notion of normal, feminism goes beyond gender differences to encompass diverse identities that enable the manifestation of multiple gender subjectivities. Garland-Thomson therefore emphasizes the importance of feminist disability studies. She argues that the gendering of disability not only "recognizes the differences among the wide variety of stigmatized forms of embodiment that constitute disability in its broadest conceptualization," it also "calls attention to the hidden norm that lurks behind our understandings of disability, one that makes some bodies seem naturally deficient or excessive and others seem superior" (Garland-Thomson, 2005, pp. 1558-1559). Thus, the intersectional alliance of disability studies and feminism helps to enlighten oppressive social scripts and liberate both disabled and nondisabled people.

Applying such intersectionality in disability and gender studies, some researchers provide empirical evidence of the discriminations suffered by disabled women. Most of these explorations center on women's experiences in fields like education, employment, and earnings. Existing literature shows that in the US and UK labor market, disabled people who are also women or members of other minority groups encounter dual discrimination in their workplace experiences (Jones, Latreille, \& Sloane, 2006; Randolph, 2005). Data from the Income and Program Participation Survey from 2004, in the United States, indicate that approximately $10 \%$ of the observed wage differential for men and $20 \%$ for women is potentially attributed to disability-related discrimination (Baldwin \& Choe, 2014). In Australia, compared to their male counterparts, female employees with disabilities are also more negatively susceptible to precarity of work and unemployment (Oguzoglu, 2016). Even when disabled women have better educational backgrounds, they have lower employment and earnings than their male colleagues. The disturbing evidence is that gender employment and earnings gaps continued to expand even after interventions such as vocational rehabilitation services had been launched in the United States (Mwachofi, 2009). Situations in developing countries remain unfavorable as well. For instance, in South Africa disability intersects with gender as well as race to disadvantage women in education, employment and income; among disadvantaged people in South Africa, black disabled women are the most disadvantaged (Moodley \& Graham, 2015).

In China, according to the latest official statistics, there are $85,020,000$ disabled people (approximately $6.21 \%$ of the total population; see China Disabled Persons' Federation, 2012). Among them, 17,040,000 are of working-age-aged 16 to 60 for males and 16 to 
50 for females-while 9,524,000 (55.9\%) are currently employed (The Central People's Government of the PRC, 2019) There exists statistically significant gender differences in employment among people with disabilities. Yet, this is an under-researched issue. A few exploratory studies show that men with disabilities encounter less discrimination than their female counterparts in the jobseeking process and have better career development prospects. For example, in both urban and rural areas, the employment rate of disabled men is higher than that of disabled women (Chen, 2018). The number of child births is negatively related to the employment rate and quality of employment of disabled women, while it barely affects the employment opportunities of disabled men (Chen, 2019). Also, educational attainment has positive effects on the probability of choosing employment for the disabled, especially for the female disabled (Xing \& Wang, 2016), while household income and being married show weaker relationships with employment among disabled women than men (Wang \& Li, 2018).

Although the discriminations and disadvantages encountered by disabled women in the workforce have been documented in detail, knowledge of these women's coping strategies is insufficient. Much existing literature examines participation in workplacebased disability management programs and the strategy of 'going the extra mile.' However, disability management interventions are mostly accessed by people who work in large companies that have enough resources to establish a disability management system and provide health care services (Jones, Tanigawa, \& Weiss, 2003; Pomaki, Franche, Murray, Khushrushahi, \& Lampinen, 2012). Likewise, the approach of earning respectability by working extra hard and performing at a higher standard may be applicable only to women with higher-paying and management-level government jobs (Moloney et al., 2019).

How women with disabilities deal with the challenges and figure out strategies to increase their life chances remain poorly understood. In addition, most studies focus on the experiences of disabled people who work in traditional, face-to-face settings. Although statistics indicate that there exists a digital divide between people with and without disabilities in Internet access and use in both the United States and many European countries (Dobransky \& Hargittai, 2006; Scholz, Yalcin, \& Priestley, 2017), more and more technologies and platforms are emerging that enable disabled people to benefit from the online access and foster their participation in social and economic life (Domingo, 2012). An example of this in China is the rapid development of information communication technologies, which allows disabled people to take advantage of the wave of 'Internet + disability' and transform themselves into new self-enterprising subjects (Lin, Zhang, \& Yang, 2019). People with disabilities use popular social media platforms to better satisfy their information needs with respect to work, living services, leisure, entertainment, etc. (Wang, Wu, Yuan, Xiong, \&
Liu, 2017). The disabled even use the Internet to create active constituencies and develop online activism to empower the disabled population (Qu \& Watson, 2019). However, studies also show that policy support for the development of information accessibility for disabled people is still insufficient, which worsens the digital divide and employment inequalities for people with disabilities. This is especially true in less-developed ethnic areas (Gao \& Fan, 2018; He, 2018).

In view of this, our study contributes to understanding of the field in two ways. First, given that disabled people experience multiple forms of discrimination and that disability and gender intersect to bring about even more negative outcomes for women in China (Dauncey, 2013; Kohrman, 2005), our study enriches the understanding of how disabled women counter stereotypes and cope with the adversity in the workplace and in their social lives. Second, by presenting the experiences of five disabled women in the cyber workforce, this article explores how the Internet economy facilitates economic and social inclusion of disabled women. We also discuss how cyber work serves as both an opportunity as well as a challenge for disabled women.

\section{Profiles of the Research Participants and Research Methods}

In this study, we take five disabled women as casestudies. All these women use social media as tools and/or platforms to work in different professions such as ecommerce service provider, salesperson, editor and vlogger. Their age ranges from 23 to 51 years old and their annual income ranges from 30,000 to $250,000 \operatorname{RMB}(4,200$ to 35,000 USD). Four of them grew up in small towns and now live in bigger cities with husbands or by themselves, only one girl who grew up in Guangzhou, a metropolitan city in south China, never experienced migration. One woman has a college degree, one finished six years of education in a vocational school for the blind, two women only received four to five years of school education (which equals a fifth-grade education), and one had never been to school but was homeschooled by her parents. They have different levels of physical impairments since birth or due to disease. One woman is married and has a 3-year-old daughter. One is married without children. The other three are unmarried and without children.

Finding participants for this study was not easy since many disabled women don't like to talk about their disabilities. The third author of this study is a former volunteer at a non-profit organization for people with disabilities and managed to find the participants by snowball sampling. The principle of choosing participants was to maximize the variation of the participants in terms of their family background (from a rural or an urban area), education (with or without a higher education degree), profession, marital status, level of physical impairments. The diversity may provide a rich, contextualized under- 
standing of the changing nature of disabled women's lives given the new availability to Internet. It is not our goal to generalize their experiences but rather to help the reader understand the significance of their experiences and what makes them worthy of study (Seawright, Jason, \& Gerring, 2008)

Most of the interviews were undertaken using social media. Besides online chat, two women also agreed to be interviewed face to face. They were all asked about experiences of growing up, work, choices in relationships, daily life, needs and expectations. We also collected and analyzed their vlogs, posts, media interviews, and comments from their followers. How these women perceive and how they interpret their own perception is the focus of our analysis of the intensive qualitative data.

All names in this article are pseudonyms. Even though one of the participants, Nana (pseudonym), is a popular vlogger known widely as the "brittle bone lady," she would still like to share her stories with even broader audiences. Findings and discussions of the present research were sent to all participants for their feedback, and we obtained their consent to publish it in English.

\section{Seizing Opportunities in the Cyber Workforce and Networking: Social Media as a Disguise}

All five women had work experience before they joined in the cyber workforce. However, they all complained about being treated unfairly in work arrangements and salaries compared to other colleagues. In the words of one of the participants, social media gives them opportunities to be "normal" (zhengchang) in the workforce. Since the 1990s that state propaganda has been encouraging disabled people to become socially and economically productive 'able-bodied people' (jianquanren), and the latter still constantly need to deal with stigma regarding disability (Dauncey, 2013). In this context, social media serves as a cover for these women to conceal their disabilities in order to better sustain themselves in the job market online.

25-year-old Nana is a wheelchair user because of brittle bone disease. She used to be an after-sales service provider who could work from home. However, she did not like this job because it was "boring and with little payment." With the developing of social media, she grabbed the opportunity and became a popular vlogger. In her vlogs, she is known as a brave and hilarious "brittle bone lady" by her followers.

51-years-old Lily is a WeChat agent for Chinese herbs. It is worth noting that Weishang, WeChat's online shopping platform used to attract potential customers $(\mathrm{Ng}$, Huang, \& Liu, 2016), is a noticeable example of freelance work popular among disabled women. In 2017, active users of WeChat reached 30 million; the WeChatdriven information consumption accounts for $4.7 \%$ of China's total information consumption, which ushers a new era of the digital economy (CAICT, 2018). Before joining Weishang, Lily has tried many business ideas such as a beauty shop, bridal boutique and an online shop selling rare coins. Eventually she built her own WeChat business to sell Chinese herbs. However, the business is not very promising because of its low entry barrier and high competition. Lily insists she is not "using disability" to attract customers. "People won't patronize your business only because you are disabled. On the contrary, they may doubt your professionalism," she said. 23-years-old SS (abbreviation of the nick name Second Sister, a common nickname in China) is an editor of a website. She never discloses her disability to her colleagues because of similar considerations. Social media becomes a viable platform to cover their disabilities.

The other two participants use different strategies both to cover and to disclose their disabilities via social media under different circumstances. 31-year-old Kitty has never left the wheelchair since she was five years old because of infantile paralysis. She never went to school. When she was a little girl she worked in her mom's grocery store. At age 26 , she left her home in the countryside and moved to Shenzhen. In Shenzhen, Kitty lives alone but does not reject help from neighbors and volunteers from non-governmental organizations. In front of these people she discloses her disability, and social media facilitates their interactions. For example, every time she receives help from her neighbors, she updates her WeChat moments (pengyou quan, which literally translates to 'friends' circle') to express her gratitude. All these neighbors are her WeChat friends, thus they can read her posts and keep interacting with her online. She also contacts NGOs by email or phone calls, inquiring about the services or benefits she could get. Sometimes she even participates as an active representative of disabled people and appears in media reports. Kitty states:

I don't hide myself [in these cases], and I feel proud of being a capable woman. When other women in wheelchairs know what I'm able to do, they are encouraged to reach out and even live by themselves as well.

However, Kitty never discloses her disability when she works online selling cosmetics and skin care products. In the interview, she explains her consideration: "My customers don't have to know my situation [with disability], otherwise they probably think I am selling my 'miserableness,' instead of cosmetics. I don't like that and I don't need it."

Besides working as an online salesperson, Kitty has another part-time job-providing an "emotional companion [through] live chat services [qingganpeiliao]." Her colleagues include housewives, college students, and some other disabled people. Providers of this service are mostly women. They use voice call or video call in social media to provide "emotional companionship" to their clients, most of whom are men. "Except pornographic and illegal information, we chat about everything," Kitty said. For example, she is not allowed to eat a banana in 
front of the camera as such an activity is forbidden according to the work instructions. Nonetheless, she has certain ways to engage with the clients emotionally and let them fantasize that they are cared for by a "young and beautiful" woman. In this job, Kitty does not disclose her disability either. She understands that her "charm" is one of the key elements to attract and keep the clients.

27-year-old Xiaojia is a makeup advisor. In her vlog channel, besides sharing makeup skills, she also promotes some skin care products she represents. In her spare time, she is active in participating in welfare programs for the blind. Her husband is also an activist in this area. Both of them are visually impaired, but their 3-yearold daughter is a fully sighted girl. Soon after their daughter was enrolled in kindergarten, Xiaojia joined a WeChat group of mothers of children in her daughter's class. She interacted with them frequently but never mentioned anything related to her visual impairment. Regarding their offline interactions, in the first few times when Xiaojia picked up her daughter in the kindergarten, none of the other mothers found out about Xiaojia's blindness as she pretended to "look at" others' eyes and responded "normally." She also presented herself well with dedicate makeup and dresses. According to Xiaojia, by successfully pretending to be a "normal mom," she won the friendship of her peers. Only after Xiaojia was certain that other mothers had taken her as one of them, she posted an article online sharing her experience as a "blind mom." This news shocked the 'moms' circle' and won her more respect and trust from other parents. Later, Xiaojia even became the leader of the 'moms' circle' as well as one of the most influential parents in the kindergarten.

The participants' thoughts and actions imply that 'normalcy' remains the aspiration of disabled women when discrimination create barriers for them in both the workforce and their social lives. Only when they are convinced that their "special situation," in their own words, could be transformed into an asset and earn genuine respect from others in some cases, they would disclose their "secret." When they felt that the existing social rules might not adequately protect them from discrimination, social media worked as a cover for them to better situate themselves in the society. This may be a consequence of state propaganda encouraging disabled people to become "responsibilized disabled citizens" and "able-bodied people" (Dauncey, 2013, p. 137; see also Dauncey, 2012) since the 1990s, and that the market reforms once stimulated "the need and desire for welfare assistance" and "made such assistance embarrassing" (Kohrman, 2005, p. 165). The participants endeavor to achieve economic independence so as to distance themselves from the stigmatic negative connotation of disability status in popular discourse. It is also worth noticing that even when they choose to disclose their disability status, it is related to the creation of new narratives of disability experience, and not to identify with the "disabled crowd" for personal and social benefit as observed in previous research (Dauncey, 2013).

\section{Empowerment of Disabled Women in the Cyber Workforce: Social Media as an Aid}

Disabled women are among the most disadvantaged and marginalized groups in society. Their physical impairments and the disability discrimination they suffer hinder their access to resources necessary for improved livelihoods, exacerbating their vulnerability and social exclusion. Findings of this study suggest that Internet accessibility may help bridge the divide of disabled people and the mainstream society. The experiences of these participants demonstrate that the digital economy and the relevant cyber workforce can help to enhance the economic and social participation of disabled women. These women also try their best to get in, stay in and get on in this specific work environment.

\subsection{Economic Inclusion: Financial Gain and Increased Life Chances}

With the emergence of the Internet economy, disabled women have more options of employment. The present case studies suggest that flexible working arrangements are the key characteristic that makes the cyber workplace especially attractive to disabled people. Internet employment takes many forms, which includes full-time, part-time, flexible time employment, entrepreneurship, etc. It allows disabled women to choose the appropriate employment style according to their different capability and physical conditions. The option of working from home is another crucial reason why the participants prefer Internet employment. As for the economic activities taken by disabled women, some count as employment such as being an editor and in customer service. Others are better described as self-employment or freelancing like being a vlogger or an e-commerce store owner. All participants considered freelancing as being more attractive. According to them, they earn more and feel better as freelancers.

For instance, the trend of Weishang exerts significant impact on the life of the participants. Except SS, who works as an editor for a website, four of the participants have their own WeChat businesses. Lily sells Chinese herbs. Kitty is a WeChat agent for cosmetics and skin care products. After marrying her husband and settling down in Malaysia, Nana and her Malaysian husband also use social media platform to provide transnational e-commerce services. WeChat businesses has gradually become an important source of income for these women. Simultaneously, it increases their social participation and social impact. This is especially true for Xiaojia. Besides offering courses on image enhancement for disabled people, she has two other jobs. While working as an agent for cosmetics and skin care products, she also has a WeChat public account in which she uploads articles about knowledge of makeup, skin care, fashion trend, and even parenting skills. She updates this account every day and has gradually become a KOL (what they call in 
marketing a key opinion leader). As her public account attracts more and more followers, Xiaojia makes use of this platform to promote the products that she represents and benefits from financially. Meanwhile, her activity on social media helps her to make a name for herself, which in turn facilitates her welfare program of offering courses for disabled people.

Besides WeChat businesses, the participants also actively explore other types of economic activities in cyberspace. Kitty's experience of providing "emotional companion live chat service" is a case in point. With the advantage of her attractive face and communication skills, Kitty earns 5,000 to 6,000 RMB (700 to 840 USD) every month from this channel. Coupled with the income she gains from WeChat business, she sustains herself quite well in Shenzhen.

While enjoying the freedom and flexibility of their economic activities in the cyber workforce, all the participants emphasize that they benefit most from the income and increased life chances brought by Internet employment. The capability to sustain themselves and to make financial decisions independently leads to a series of changes in the lives of disabled women. First, income from the Internet employment brings disabled women a sense of security. As they earn more, not only do they have greater capability to deal with risks, they also have more freedom to enjoy life. A post in Kitty's WeChat Moments illustrates this clearly:

I work hard to earn money and to earn a life that I can buy whatever I want, go whenever I want, afford the medicine when I get sick, and invite my best friends to dinner....Self-sufficiency allows one to live a life with dignity.

Second, financial independence enables disabled women to live alone and achieve autonomy. Four of the five women have moved out of their parents' house and live independently. The exception, SS has also submitted the application of public rental housing herself and plans to "live a more convenient life." For these women, living alone has a symbolic meaning. It signifies that they are capable of taking care of themselves. They are trying their best to tear down the negative labels of incapability and 'being a burden' that often attaches to disabled people. The process of moving out of their parents' house also facilitates the building of self-confidence and autonomy. This echoes Dauncey's (2013) finding that by distancing themselves from the stereotypical "disabled crowd," some disabled people offer alternative narratives of disability, which in turn facilitate their self-empowerment.

Third, self-sufficiency makes it possible for disabled women to take more control of their love lives. 51-yearold Lily enjoys her single life. She doesn't consider marriage as a necessity. "I've prepared the money to go to the nursing home when I'm old," she said. With a good economic condition, she gains support from her family of her life choice. 31-year-old Kitty faces parental pressure to get married, but she does not compromise. She insists on finding the right person. In the interview, she straightforwardly criticizes disabled women who get marry to find a caretaker as "indecisive," "incapable," and "unambitious." For 23-year-old SS marriage is still far away. She hasn't had any sexual experience. In the interview, SS admits frankly that her current concern is to find a sex partner. She has even planned to move out of her parents' house "so as to have more freedom to arrange [her] private life."

In public discourse, the image of disabled people that is often constructed is they are incapable and dependent (Nario-Redmond, Kemerling, \& Silverman, 2019). Findings from these cases indicate that the income from Internet employment helps disabled women to fight such stereotypes. Financial independence not only allows them to support themselves, it also increases their control over their lives. For these women who are often marginalized and whose images are often derogatorily described, such progress is worthy of attention and recognition.

\subsection{Social Inclusion: Boosting Self-Confidence and Finding Voice}

While developing multiple ways to get in and get on in Internet employment, disabled women also acquire resources that facilitate further social inclusion. Participation in the cyber workforce expands their social network. Dealing with various kinds of people online motivates them further to examine their relationship with the society and their self-awareness. The experience of overcoming difficulties along the way makes them more tolerant and self-assured. For example, when working as a live streamer, Nana used to receive malicious feedback. In the interview, reflecting on this experience, she told us that the things that once hurt her remind her of the things she cares about. Such reflection furthers her selfawareness and self-confidence:

I always wanted to live a decent life, and I used to think that having expensive and gorgeous things is the symbol of decency. Thus I once tried to save money to buy luxury goods and show off the things I have.....Later, I realized that one will never be at ease if she can't appreciate herself and recognize the value of her life....The real decency is self-acceptance. It doesn't require anyone's approval or recognition.

In addition, cyberspace enables some disabled women to make their voices heard and influence others' lives. For instance, in her public account on WeChat, Xiaojia often uploads articles to help her followers understand more about the lives of people with disabilities. Through live streaming platforms and live chat services, Nana and Kitty provide comfort and hope to many people, which is also a way to enhance their social participation and contribution. 
Both the self-sustainability and social inclusion resulting from Internet employment contribute to destigmatizing disabled women. To some extent, they also facilitate the demystification and de-stigmatization of this group of women.

\section{Risks and Challenges Encountered by Disabled Women in the Cyber Workforce}

When disabled women enter the labor market, they encounter many difficulties regardless of their occupation. Because of their physical challenges and the structural constraints, compared to other employees, they are more disadvantaged. Although Internet employment provides these women more opportunities for economic and social inclusion, it also brings them many risks and challenges. These five cases show that cyberbullying, harassment, insufficient skills and competitive edge are the major issues that bother disabled women in the cyber workplace.

The discomfort and pain brought by malicious speculation, prying gaze and even bullying are often increased as people find themselves in the diverse and less regulated social environment of cyberspace. For example, in the live streaming platform, Nana encounters attacks from at least five strangers every day:

The moment they saw me sitting on a wheelchair and doing live streaming they started to insult me as Internet beggar. They don't care what I said. They just assume that I'm using my physical condition to do a begging scam.

According to Nana, her dignity was "seriously trampled on" because of such experience. Kitty's story is a bit different. When providing her "emotional companion live chat service," she never discloses her disability status to her male clients. She admits that concealing her physical condition helps to avoid the risk of losing clients. As Kitty admits, the live chat service targeting male clients unavoidably involves some emotional and sexual innuendos. A disabled female body is usually not a sexually attractive object to the ordinary male gaze (Solvang, 2007). Meanwhile, people with disabilities are often collectively imagined as defective (Garland-Thomson, 2005), rather than people who destabilize the conventional standard of normalcy. Therefore, it is difficult for disabled women to take advantage of their disability status in such a context. Given the risks of losing clients or being harassed, concealing their disability is an understandable strategic choice.

For disabled women who choose to join the cyber workforce as entrepreneurs, many of them are troubled by their insufficient business knowledge and skills resulting from their relatively low educational attainment and limited social experience. 51-year-old Lily is the eldest of the five participants. She did not continue her study after graduating from technical secondary school.
In the past 20 years, like many people who venture into in the market economy, with an 'opportunist' mindset, Lily keeps venturing on everything that seems profitable. Nonetheless, even though she could earn some money at first, most of her business ideas failed as more competitors appeared. "When you don't have a technical advantage or any competitive edge, it's very difficult to survive," she said.

Before working as a freelance lecturer and running her one-person WeChat business, Xiaojia used to have more than 30 employees when she first got her sales contract for the skin care product she represents. Many of these employees were also disabled women. However, even with the ambition to make a difference to the lives of disabled women, she encountered a serious loss of employees due to a lack of management skills and finally decided to disband the team.

The participants also mention other challenges they encounter in Internet employment. For example, there is inadequate legal protection and insurance coverage for disabled people when they participate in the cyber workforce. Compared to other employees, disabled women are more vulnerable to risks brought by cyberbullying, sexism, precarity of work, and unemployment. When institutional protection is insufficient, disabled women can only turn to their families for help and support. Some of them are unaware of their right to request accommodations in the workplace. Some women refrain from seeking extra support to avoid being negatively typecast. Therefore, many disabled women share the mindset that the only way to fare well and to maintain dignity is to earn as much money as possible. However, even though they are eager to fair well, their insufficient knowledge and skills often hinders their career development in the fast-changing and highly competitive cyber workplace.

\section{Discussion and Conclusion}

Scholars point out that disability is both a sphere of existence and a socio-cultural formation (Deutsch \& Nussbaum, 2000; Garland-Thomson, 2005). Disabled people also constantly re-define their identity in the light of different circumstances (Kohrman, 2005). For example, in China, some disabled people identify with the "disabled crowd" to gain social and personal benefit, some prefer distancing themselves from the same crowd and endeavoring to create alternative narratives of disability experience (Dauncey, 2013). In this study, we examine different experiences of disabled women and how these women actively increase their life chances in the developing market economy in China. Since the focus of our study is the economic and social inclusion of disabled women, the participants' thoughts and actions of re-imagining and re-defining the experience of disability are highlighted. The five cases studies demonstrate that due the influence of urbanization, migration, modern womanhood and especially the booming Internet economy, Chinese disabled women have more opportunities 
to become independent financially, socially and ideologically. In the cyber workforce and in their relevant social lives, they act as qualified employees, entrepreneurs, family breadwinners, leaders of social groups, activists in welfare programs, as well as spokeswomen for disadvantaged people in media reports. Their life stories have significant meaning in facilitating our understanding of gender and disability in a fast-changing world.

It is worth noticing that some of the participants would not have achieved what they have today without the help of NGOs and relevant activities targeting people with disabilities. In social interaction and within the ordinary workforce where an ideological commitment to the social inclusion of disabled people is downplayed (Nario-Redmond et al., 2019), many of these women still try to disguise their disabilities so as to avoid discrimination and exclusion. Under such circumstance, social media can work as an irreplaceable tool that can blur the boundaries between 'normalcy' and 'specialness,' enabling disabled women to become equal players with others in many social activities. Simultaneously, we have to be cautious that the participants' experience of increased economic and social inclusion with the help of social media does not cause us to ignore the fact that more productive intervention programs offered by the government and quasi-governmental organizations for disabled people in China are needed. Future research may further examine how such intervention could be accessed by more disabled women and how the effectiveness of these programs could lower the possibility of exposing people's disability status and evoking social stigmas.

We also must admit that empowered by web accessibility, the women in this study are 'luckier' than many others who are disadvantaged because of their physical, socio-cultural and economic conditions. For example, the severity of participants' disabilities were such that they could rely on some adaptive hardware such as an alternative keyboard or a screen-reader to access the Internet. However, for people who suffer from severe disabilities such as muscle atrophy or spinal cord injuries, using a computer can be extremely difficult and prevent them from participating in today's digital society. Further studies are needed to explore the challenges faced by people with intellectual disabilities to determine how they might be aided to overcome the forces of social exclusion.

All five participants live in urban areas, three in the first-tier cities of Beijing, Guangzhou and Shenzhen. Geography significantly affects the experience of disability. For residents with a local hukou (a household registration record which officially identifies a person as a local resident) in these big cities in China, people with disabilities have access to social welfare which covers most of their medical and life expenses. Disabled people in big cities also benefit from better transportation, accommodation and support from volunteers and volunteer organizations. However, around $80 \%$ of disabled peo- ple in China are rural residents (Kohrman, 2005, p. 24). Disabled people with a rural hukou often do not have the opportunity and capability to migrate and settle in big cities that offer a friendlier environment for people with disabilities. Due to an absence of enforcement mechanisms, the implementation of disability programs is also less effective in the rural settings. Disabled people in rural areas often lack the education, social status and political connections to pursue their rights and receive the assistance provided by government and institutions such as the China Disabled Persons' Federation (Kohrman, 2005). Therefore, further research is required to explore how Internet accessibility and the new opportunities provided by the Internet economy can be harnessed to expand the life chances of disabled people living in less favorable conditions.

\section{Acknowledgments}

We would like to thank all the participants in this study.

\section{Conflict of Interests}

The authors declare no conflict of interests.

\section{References}

Baldwin, M. L., \& Choe, C. (2014). Re-examining the models used to estimate disability-related wage discrimination. Applied Economics, 46(12), 1393-1408.

CAICT. (2018). WeChat economic and social impact report 2017. Beijing: China Academy of Information and Communications Technology.

Chen, P. (2018). Comprehensive employment of disabled people and its influential factors: An analysis based on empirical statistics of Chinese urban and rural citizens. Journal of Shandong Academy of Governance, 158(1), 34-41.

Chen, T. (2019). The impacts of the disabled women's fertility on their employment. South China Population, 34(3), 49-58.

China Disabled Persons' Federation. (2012). Notice regarding the use of the total number of disabled people in the country at the end of 2010 and the number of people with different types and different disabilities levels (Paralympic Federation Policy Document No. 25). Beijing: China Disabled Persons' Federation. Retrieved from http://www.cdpf.org.cn/zcwj/ zxwj/201203/t20120312_38275.shtml

Dauncey, S. (2012). Three days to walk: A personal story of life writing and disability consciousness in China. Disability \& Society, 27(3), 311-323.

Dauncey, S. (2013). A face in the crowd: Imagining individual and collective disabled identities in contemporary China. Modern Chinese Literature and Culture, 25(2), 130-165.

Dauncey, S. (2017). Gentlemen, heroes, real men, disabled men: Explorations at the intersections of dis- 
ability and masculinity in contemporary China. Nan Nü: Men, Women, and Gender in Early and Imperial China, 19(2), 357-384.

Deutsch, H., \& Nussbaum, F. (2000). Defects: Engendering the modern body. Ann Arbor, MI: University of Michigan Press.

Dobransky, K., \& Hargittai, E. (2006). The disability divide in internet access and use. Information, Communication \& Society, 9(3), 313-334.

Domingo, M. C. (2012). An overview of the Internet of Things for people with disabilities. Journal of Network and Computer Applications, 35(2), 584-596.

Gao, Y., \& Fan, S. (2018). Status and policy suggestions on teleworking of persons with severe disabilities in Internet era. Disability Research, 32(4), 72-78.

Garland-Thomson, R. (2005). Feminist disability studies. Signs: Journal of Women in Culture and Society, 30(2), 1557-1587.

He, Q. (2018). Study on employment assistance for persons with disabilities in ethnic areas under "Internet plus" era. Disability Research, 30(2), 61-67.

Jones, M. K., Latreille, P. L., \& Sloane, P. J. (2006). Disability, gender, and the British labour market. Oxford Economic Papers, 58(3), 407-449.

Jones, D. L., Tanigawa, T., \& Weiss, S. M. (2003). Stress management and workplace disability in the US, Europe and Japan. Journal of Occupational Health, 45(1), 1-7.

Kohrman, M. (2005). Bodies of difference: Experiences of disability and institutional advocacy in the making of modern China. Berkeley, CA: University of California Press.

Lin, Z., Zhang, Z. a., \& Yang, L. (2019). Self as enterprise: Digital disability practices of entrepreneurship and employment in the wave of 'Internet + disability' in China. Information, Communication \& Society, 22(4), 554-569.

Moloney, M. E., Brown, R. L., Ciciurkaite, G., \& Foley, S. M. (2019). "Going the extra mile": Disclosure, accommodation, and stigma management among working women with disabilities. Deviant Behavior, 40(8), 942-956.

Moodley, J., \& Graham, L. (2015). The importance of intersectionality in disability and gender studies. Agenda, 29(2), 24-33.

Mwachofi, A. K. (2009). Gender difference in access and intervention outcomes: The case for women with disabilities. Disability and Rehabilitation, 31(9), 693-700.

Nario-Redmond, M. R., Kemerling, A. A., \& Silverman, A. (2019). Hostile, benevolent, and ambivalent ableism: Contemporary manifestations. Journal of Social Issues, 75(3), 726-756.

Ng, J. C. Y., Huang, M. M. D., \& Liu, Y. (2016). The 'feminine' entrepreneurial personality trait: The competitive advantage of female college-student entrepreneurs in Chinese Weishang businesses? Asian Business \& Management, 15(5), 343-369.

Oguzoglu, U. (2016). Disability and multi-state labour force choices with state dependence. Economic Record, 92(296), 28-46.

Pomaki, G., Franche, R.-L., Murray, E., Khushrushahi, N., \& Lampinen, T. M. (2012). Workplace-based work disability prevention interventions for workers with common mental health conditions: A review of the literature. Journal of Occupational Rehabilitation, 22(2), 182-195.

Qu, Y., \& Watson, N. (2019). Gathering in a cyber world: Internet use of Chinese disabled people and the emergence of disability constituencies. Disability \& Society, 34(7/8), 1062-1081.

Randolph, D. S. (2005). The meaning of workplace discrimination for women with disabilities. Work, 24(4), 369-380.

Scholz, F., Yalcin, B., \& Priestley, M. (2017). Internet access for disabled people: Understanding sociorelational factors in Europe. Cyberpsychology: Journal of Psychosocial Research on Cyberpspace, 11(1). https://doi.org/10.5817/CP2017-1-4

Seawright, J., \& Gerring, J. (2008). Case selection techniques in case study research. Political Research Quarterly, 61(2), 294-308.

Shang, X. (2000). Bridging the gap between planned and market economies: Employment policies for people with disabilities in two Chinese cities. Disability \& Society, 15(1), 135-156.

Solvang, P. (2007). The amputee body desired: Beauty destabilized? Disability re-valued? Sexuality and Disability, 25(2), 51-64.

The Central People's Government of the PRC. (2019). China continues to promote high-quality development of employment for people with disabilities in the new era. The Central People's Government of the PRC. Retrieved from http://www.gov.cn/xinwen/ 2019-10/28/content_5445595.htm

Wang, C., \& Li, M. (2018). Gender differences in employment among people with disabilities in China. Journal of Disability Policy Studies, 29(1), 12-21.

Wang, W., Wu, Y. C. J., Yuan, C.-H., Xiong, H., \& Liu, W.-J. (2017). Use of social media in uncovering information services for people with disabilities in China. The International Review of Research in Open and Distributed Learning, 18(1). Retrieved from http://www. irrodl.org/index.php/irrodl/article/view/2621/4038

Xing, Y., \& Wang, S. (2016). Employment of the disabled: The influence factors of education, degree of disability and gender. Education \& Economy, 6, 47-54. 


\section{About the Authors}

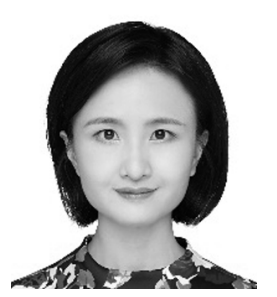

Jing Zheng is an Assistant Professor in the Department of Sociology at Shenzhen University, China. She obtained her PhD from the University of Hong Kong. The key questions guiding her research work are how changing intimate relationships are situationally shaped by local social, cultural, and material circumstances in different societies, and how public policies affect the well-being of individuals and families. Her works have been published in Chinese Sociological Review, Families, Relationships and Societies, and Frontiers: A Journal of Women Studies.

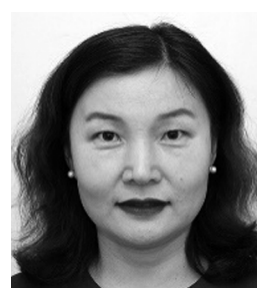

Yuxin Pei is an Associate Professor in the Department of Sociology and Social Work at Sun Yat-sen University, China. She got her PhD from the University of Hong Kong. Her research interests focus on women's studies and social work intervention. She is also an expert on disaster social work, gender studies, and women's sexualities. Her works have been published in Women's Studies International Forum, Journal of Sex Research, and Culture, Health \& Sexuality: An International Journal for Research, Intervention and Care. From 2014-2015, she visited University of Southern California as a Fulbright scholar.

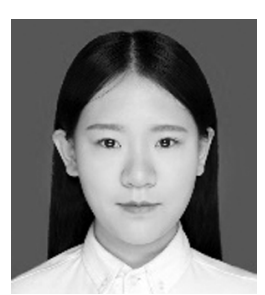

Ya Gao is a Social Worker in Shenzhen, China. She got her MSW from Sun Yat-sen University, China. She works closely with disabled people. 